\title{
DEAF PARENTS OF DEAF CHILDREN
}

Ava Buzzard and Sue Nicholson

\begin{abstract}
Our purpose in writing this paper is to share our stories with other Deaf and hearing parents of Deaf children in the hope that we can learn together so that all Deaf children can prosper. Our paper makes a case for all Deaf children having access to Deaf adults early in their lives. We describe how we felt when our children were diagnosed as Deaf, and we talk about visual communication and our use of this in assisting our children to begin school with good language skills. We emphasise the importance of literacy, the use of technology and the value that we place on spoken language. Our response to advice that professionals give is described in the context of our Deaf way. We share a vision of what the socialisation of Deaf children should entail and the expectations that we should all have for our Deaf children.
\end{abstract}

\section{INTRODUCTION}

In this paper we tell our stories of the highs, lows and complexities we experience being Deaf parents of Deaf children. We go on to identify some of the benefits that Deaf children have when they are born into Deaf families. We discuss our perspectives on language learning, particularly New Zealand Sign Language (NZSL), and how we see literacy as centrally important in children's language development. Education is highly valued, because if our children achieve academically, they can more easily address the challenges of living in both the Deaf and hearing worlds. The value we place on technology is discussed in the context of Deaf culture. Also discussed in this context is the professional advice on parenting that Deaf parents receive.

We are both Deaf parents of Deaf children. We raised our children in different cities in New Zealand and had little contact with each other due to the distance and the ages of our children. It is therefore interesting now to see how strong the similarities are between our views and our experiences. 
The process of writing this paper was complex. It involved translating several conversations and conference presentations from NZSL into written English. Aspects of our stories have been presented before at the Deaf View Conference (2004), the Anthropology Conference (2004) and the Family Book (2005. A video exists of the presentation that was given at the Deaf View Conference.

Rachel Noble, Shannon Knox and Tricia Laing have worked with us in preparing this extended version of our stories. Rachel assisted with the original presentations at the Deaf View Conference and in the Family Book. Tricia watched the presentations at the Deaf View and Anthropology Conferences and wrote the Power Point presentation into a draft text. Shannon interpreted the presentation at the Anthropology Conference and, with Rachel, helped us review the draft and complete the story as it appears here.

We have indicated who is telling their story by putting one or both of our names at the beginning of the paragraph.

NEW MUMS TO BE

Sue and Ava: When we were pregnant with our first babies we had no reason at all to think that our children may be Deaf. We were certainly looking forward to the arrival of our babies.

Ava: My husband and I had two hopes for our baby, one was that it would be a boy, and the other that he would be hearing so that he could tell us when there was someone knocking at the door, to make telephone calls for us, to be our 'ears' at home. If our second child was Deaf, that would be ok.

Sue: Just after Tessa was born, her father tested her hearing by clapping his large hands and Tessa responded by blinking. I was so relieved to see this and thought all was fine, the baby was a normal hearing child.

\section{DIAGNOSIS}

Ava: When Ben was around six weeks old we took him to have a hearing test. During the first test Ben was restless so we went back for a second test. My mother (hearing) came with me. They put the equipment of Ben's head and went away to do the testing. The audiologist did not know how to tell me that my baby was Deaf so he came through the door waving his harms in a 'thumbs down' movement! Imagine hearing that your son is Deaf in this way! I was shocked, and my mother burst into tears. However, my mother also said 
to me at the time that there was nothing wrong with this baby; he was only Deaf, just like his parents and uncle.

We went home and waited for my husband to come home. When we told him the baby was Deaf he couldn't believe it. He was shocked, too. I realised that we had been wrong to hope for a hearing baby to do things for us. We were responsible for bringing up this child, whether he was Deaf or hearing. I realised that the responsibility is the same for hearing parents bringing up a Deaf baby, they are responsible to raise the baby - in the same way as my Deaf husband's hearing parents had to raise him.

Sue: At the age of three months, my family doctor wanted to double check Tessa's hearing. I took her to the National Audiology Clinic on my own. They put electrodes on Tessa's head, and as they were doing the tests I could see the audiologists' faces drop. I said, 'Tessa can't be Deaf because she heard the clapping.' They explained that Tessa was not totally Deaf but had significant hearing loss. This was the worst day of my life. When Blair got home later, his first reaction was to go to the bedroom and cry.

The doctor was puzzled by the cause of Tessa's deafness. We visited a specialist who asked if my mother had any evidence proving that she had had German measles, as we had come to believe that this was the reason I was Deaf. We soon learnt that the cause of my deafness was genetic, and that I had passed this on to my baby daughter. Hearing this after thirty-three years came as a huge shock to me, and also to my mother, who was still coming to terms with the fact that her granddaughter was Deaf. We now knew that it was highly likely that any future children that my husband and I had would also be Deaf.

We were prepared when Simon was born. In fact, on the day that he was born I clapped loudly to test his hearing and he didn't respond!! He just slept. I was frightened as I thought that he may be totally Deaf. Finally at six weeks of age, Simon had his hearing tested. Blair came with me this time. We were relieved to learn that Simon only had a severe hearing loss, just a little more than Tessa who has a moderate-severe loss. Their hearing losses are similar to Blair's.

\section{OUR RESPONSE}

Sue and Ava: Some Deaf parents feel sad when they discover that their child is Deaf. We know that our children will have challenges in our everyday world. We believe that the quality of our children's education will have a huge impact 
on their ability to meet these challenges. Many of us did not achieve our educational potential when we were young and as a result are employed in work that is below our capability.

Sue: I have always had office jobs but I would have liked to have studied at university and had better jobs. In our time there were no interpreters, no note-takers, etc. People did not think that Deaf people could study and get better jobs.

Sue and Ava: We are determined that this will not happen to our children. Particularly, we hope that they will be strong in their self-esteem and able to resist the patronising attitudes of some people who see them as disabled rather than culturally different.

\section{EARLY ACCESS TO HEARING AIDS}

Sue: Tessa got her first hearing aids at four months of age. A lot of people thought that we were cruel and said that we should wait, but Tessa wore them and thought that they were a great teething ring! We had to put a special loop on the hearing aids to stop her from taking them off all the time.

I joined a mother's group which met once a month. This was great, I enjoyed sharing our experiences, but as the only Deaf mother, I felt isolated.

Ava: When Ben was very small an adviser from Sumner School for the Deaf came to visit me to give me advice. They explained that Ben needed to wear hearing aids. That was okay, so Ben received his first hearing aids around three months of age. Ben would constantly pull them off, and the adviser told me to keep putting them back on, like putting shoes back on a baby who keeps kicking them off.

Sue and Ava: We know that with hearing technology children can make the most of any hearing that they have. They can learn to listen and speak, which we think is important so that they can be part of the Deaf and the hearing world. We allow the children to make their own decisions about whether or not they will wear hearing aids when they are older. However, we see this use of technology from within our Deaf culture not as an alternative to our culture and language. We see ourselves as culturally distinct, not disabled. We do not see technology as able to correct a hearing disability - as able to 'make our children hearing. We think that taking this approach has led to too many Deaf children missing out on the best education, not achieving academically 
when they had the potential to do so, becoming frustrated, and having low self-esteem.

\section{BORN INTO A DEAF WORLD}

Sue and Ava: Deaf infants have the same needs as all children. It can be said that those born into Deaf families grow up in a world no different from a child who is born into any other cultural group. These children, from the time they are born, are exposed to a world where their social, emotional, psychological, cognitive and linguistic development can be maximised. This is especially true when the Deaf parents are themselves children of Deaf parents. Neither of us have had this experience, but our children may. Where Deaf families have existed for generations, and where Deaf adults have successfully made the journey to becoming strong and confident in their Deaf identity, Deaf children can flourish.

Sue: When I found out that my children were Deaf I kept them very close to me. I was embarrassed and needed time to get used to the idea of having Deaf babies. For six months the Deaf community didn't know. When our Deaf friends found out they were surprised. They accepted it quickly and went on and accepted our babies as if they were no different from any other baby. Our Deaf friends were not patronising and did not pity us. Our hearing friends were more patronising, but everyone said that because Blair and I were Deaf, and because they knew what kind of people we are, they knew that our children would be just fine.

Sue and Ava: Most Deaf parents accept and welcome their Deaf children into their families and provide stable emotional environments where children can become socialised into the Deaf world. One way to explain this natural environment is to show that Deaf children in Deaf families have full access to household events.

\section{WITHIN OUR OWN HOMES}

Ava: Before Ben turned two, a new 'Deaf world' arrived in New Zealand. The New Zealand Sign Language (NZSL) Interpreting service began, equipment such as a flashing light doorbell became available, and a TTY (telephone for the Deaf) enabled us to telephone each other! For me, this was wonderful! I could be more independent within my own home. For Ben, from the age of two, this was all very natural and normal. He has always had instant access to such things. When the doorbell rang, flashing lights flashed; we would both 
race to the door to see who was visiting! This is so different from my experience in a hearing family where I would be the last to know that someone had knocked on the door. I tell Ben that he has been lucky to have all of this access from such a young age. For him though, it is a natural part of life and he doesn't see it as lucky.

Sue: In our house we have a doorbell with a flashing light, though we don't use it; our door has glass so it is hard not to see someone come to the door! The phone has a loud ring, and of course we have a fax machine, teletext television, and a text-capable mobile phone each. We use the computer a lot for e-mails, chat, internet relay and so on. We have recently renovated our house, and we made sure that our walls were a light colour with not too many ornaments. We have good bright lighting, and some open plan spaces. All of this suits us for clear communication.

Ava: Really, to me it doesn't matter what the walls are like, I don't mind having lots of pictures and ornaments around. It is important to have clear vision so nothing blocks communication. Good lighting is very important to facilitate easy visual communication. It is also important for the kitchen and the lounge to be visually accessible. Of course, we have a teletext television, text-capable mobile phones, fax machines, computers, etc.

Sue and Ava: Deaf children of Deaf parents have access to Deaf adults from the time they are born. Their parents are usually part of a strong network of Deaf friends who become part of the child's life immediately. Often these Deaf friends are long-time friends, often having attended school together. This means that from a very early age the children are exposed to a social environment full of people who are rich language models and examples of independent living strategies. Children are also involved in visiting friends in the Deaf community. Our Deaf children see us using our visual language and they learn NZSL in the same way that other children learn their mother tongue. Children can 'overhear' conversations and thereby learn the mores, values and behaviours that are considered desirable in Deaf culture. They learn the rules of linguistics, turn-taking and interrupting as a result of parental modelling rather than being overtly taught it.

OTHER DEAF PEOPLE

Ava: Ben and I would regularly visit my Deaf brother and my hearing parents, as he is their grandson. We would also visit many of my friends, both Deaf and hearing. With our Deaf friends, Ben could look at our conversations naturally, 
decide if the conversations were interesting or boring, and if they were boring he could go off and play - just the same as hearing children who can overhear their parents' spoken conversations. Deaf friends would ask Ben questions like, 'How is school? Who is doing what?' etc. Ben would then go on to have a proper conversation with these people. With hearing people though, they would ask the same questions but the conversation would be very limited.

One thing that I must say, however, is that when Ben was with other hearing children he would happily play with them, but if they were talking about something like competitions on the radio, Ben wouldn't know what they were talking about and it was tough for him. He just couldn't join in.

Our Deaf friends were good at helping to teach Ben manners, how to talk politely, table manners, appropriate attention seeking means, etc. - for example, to tap the table gently rather than banging it loudly! They would also teach Ben how to take turns appropriately.

Sue: When our children were small, a Deaf friend of mine, Judy, was an excellent role model for our children because she was already the mother of a Deaf child. I also learnt a lot from her. One time when we were visiting Judy, Tessa was around two and Amanda (Judy's child) would have been around seven years old. Judy and I were trying to have a private conversation, but Amanda would keep peeping around the corner to watch our conversation. Judy would get mad! We had to keep changing the subject!

As a family, outings are almost always with Deaf people. Sometimes we would go out with hearing people, as Blair has a lot of hearing friends, too. Really, it was more fun to go out with Deaf people. This is because of our communication style. We know we don't miss out on any of the conversations; we talk in a fun way. Our Deaf friends will often tell our children stories from their time as young children; often these stories are part of New Zealand's Deaf history.

Ava: At the time when Ben was born there were no other Deaf families around. The Ferguson family was there, but their children were much older than Ben. When I was growing up I would look at their family and think, wow, Deaf parents and Deaf children. But now, as a Deaf family ourselves, it is good to chat with them, to share our ideas. We have different views but it has been enjoyable. My brother has Deaf children, and he chose for them to be educated within the mainstream setting at the time when Ben was going to a school for the Deaf. Again, we would talk about our ideas and views. 
There was one other Deaf family in Christchurch, the Townsends, whose children were slightly older than Ben. We didn't know each other when the children were growing up, which is really unfortunate as now, with all our children living adult lives, we have found that we had a lot in common.

Sue and Ava: Deaf people do have a different way of talking. We talk about different issues and have a different style of humour. We don't understand hearing jokes but can understand Deaf jokes fast! Our conversations with Deaf people are full and deep. Deaf families will participate in Deaf community activities such as Deaf Club.

\section{INVOLVEMENT IN DEAF COMMUNITY ACTIVITIES}

Sue: As a family we attend special events in the community, such as the Wallace Williams Comedy Evening, fundraising events, and community parties. Last year, Tessa brought one of her hearing friends to the New Year Social at the Deaf Club. She was amazed by how sociable the Deaf were!

Ava: We would always go with the Deaf Club to picnics, fancy dress parties, fundraising events, sport events, etc. Before Christmas there was always a picnic where we would play all of the usual games: egg and spoon races, sack races, three legged races, gumboot throwing, wheelbarrow races, etc. Ben always enjoyed these picnics; he enjoyed watching conversations and joining in the activities. It was all part of the pre-Christmas excitement! Ice creams were given out, and everyone knew Ben. He mixed easily with the adults and the children there. He would play with the Deaf children present and also with the hearing children of Deaf adults. One year, Father Christmas arrived on a small truck. He waved to all of the children as he arrived and would also throw lollies in a lolly scramble, which all of the children loved. After a while he would stop, and begin to give out presents by calling the name of each child. Ben was stunned and said, 'Father Christmas can sign, Father Christmas is Deaf!!' All of the other Father Christmases Ben had seen in shopping centres spoke!!

Sue and Ava: Sport is a big thing in the Deaf community. It is a very good way to meet other Deaf people from all over New Zealand. Many people meet their partners through Deaf sports.

Sue: Now that my children are older, they are both exploring Deaf and hearing sports. Simon is a very keen sports person and is a good all rounder especially with softball, rugby and soccer. Tessa enjoys playing indoor netball and net- 
ball. She has been involved with the Deaf Netball Team for five years now and playing indoor netball with her hearing friends. Simon hopes to take part in Deaf rugby in the future.

Ava: Ben and I have never been big on sport, so it was not an important thing for our family. However, it is worth mentioning the World Deaf Games that came to Christchurch in 1989. This was a major event for the Christchurch Deaf community. It was also the time when people were beginning to understand and learn about Deaf Culture. My father was a volunteer at the games, and it was a very emotional time for him. He actually cried seeing all of these confident, happy Deaf people here in Christchurch from all over the world. He wished that he had known about Deaf Culture when my brother and I were growing up. He really tried hard to learn New Zealand Sign Language (so did my mother). Dad had always adopted the Deaf way of doing things like stamping the floor, tapping the table, using expressive body language and so on. The World Deaf Games certainly had a positive impact on the New Zealand Deaf community.

\section{DEVELOPING LANGUAGE}

Sue and Ava: Deaf children of Deaf adults are confident in their language use and use sign language creatively. Along with visual language learning, literacy is highly valued. The use of captioning, teletext, fax machines, e-mail and texting all rely on good literacy skills. For these reasons, Deaf parents have an appreciation of the role of literacy in their children's lives and seek to develop literacy skills early on. We maximise interactions and discussions with our Deaf children on a wide range of activities and ideas, and we engage them in reading activities. In this way we share our views of the world and our values.

Ava: Ben has always been a strong New Zealand Sign Language user. His language has always been natural and age appropriate from the time that he was a young baby. I notice that other Deaf children with hearing parents are always very behind in their language development. They catch up later. I signed with Ben; I communicated naturally. The adviser learnt from my way. She could see that I signed, that I talked with my baby and that we had a strong visual connection. The eye contact between Ben and myself was very strong. The adviser was amazed to see this and took me to meet other hearing parents of Deaf children to show them how I communicated with my son.

Sue: At the time when Tessa and Simon were small the KDEC (Kelston Deaf Education Centrepreschool was very good. Tessa and Simon would receive 
one-to-one tuition on speech and listening skills. Both children now have good listening skills. I didn't teach them speech, but I did teach them visual language and social skills.

Both children also went to kindergarten. Tessa loved it; she loved mat time and cooking time, as there was more variety in kindergarten compared to the KDEC preschool. I felt that more learning happened there. I also enjoyed the kindergarten environment. I got on well with the mothers and the teachers there. I needed to talk to the other mothers about all of the primary schools in the area so that we could decide which school would be suitable for Tessa and Simon.

I had two very good hearing friends from this time. We used to share family birthday parties and socialise together a lot. Then one day I found out that one was moaning about the cost of keeping in touch with me through texting and e-mailing. She had a mobile phone but said that it was for emergencies only. I was hurt. I didn't like being seen as an expensive friend purely because it costs a little bit of money to contact me. Now we have no contact at all with her family.

Ava: At that time, when Ben was young, I didn't know much about preschool services. The adviser said that it would be good for Ben to go to a preschool. I said, 'Ok.' But I wasn't really very sure about what a preschool was for. I took Ben along and stayed with him. I didn't know what was going on, so I told Ben to go and play. He said, 'Ok.' But he didn't really understand what was going on. When I picked Ben up at the end of the session they would all say that Ben had been a good boy. I believed them, but I really never knew what happened there. I never connected with the other hearing parents. They all talked and talked and talked. When Ben saw me he would talk away with me. I would say 'Hello' and 'Good-bye' to the other mothers, but it was all very polite. Ben was never invited to birthday parties, and I didn't get invited to coffee groups, etc.

USING SIGN LANGUAGE

Sue: When Simon was born, my mother said not to teach him sign language. I used Signed English, which is using signs in English word order with the aim of helping to teach him English grammar. I found that Simon was behind with his language development compared with Tessa. Once I changed to NZSL Simon picked up language very quickly, and away he went with this language development. We have always used our voices for our children as well. 
Ava: At one time Ben would not drink water. I would explain that water was important, that it helped to clean the body and so on. Ben would say, 'Yuk,' and refuse to drink it. I then decided to explain to Ben how water cleanses the body by illustrating in sign language all of the systems in the body, from the mouth to the anus, all of the blood vessels, etc. I did this by holding the vessels out from the body, pouring water in the mouth then 'shaking' it as the water moved through to cleanse the body and out at the bottom. Ben's reaction was, 'Wow', and he happily drank water after that!

Ava and Sue: As a consequence of fluency in sign language, Deaf children develop positive identity and self-esteem.

\section{DEVELOPING LITERACY}

Ava: When Ben was still a baby I knew that literacy was really important. I started with puzzles; we would look at a picture of a ball, look at the word ball, and I would sign ball, and do the same for other objects, also. Soon I would mix them up and ask Ben to match the picture and the word with the sign that I gave him. I would give him a lot of positive praise. I didn't teach him about sentences, as I don't want him to have my weak English. I taught him words and vocabulary. From an early age, his language use was sophisticated.

Sue: I learnt what to do with Tessa, how to make a scrapbook to develop language through visual pictures, how to talk to her, how to read a book with her and how to sign with her. Judy was a great role model for this. It was lovely to watch her daughter Amanda reading books to my babies.

Ava: Ben used language very creatively. He would certainly add a lot of classifiers to extend the impact of what he was saying. There was one time at school when the teachers came to me to say that they were fascinated with his work. He had written a poem, as all of the children were required to do, but in his case he had expressed his poem in words describing a very visual effect. The teachers had never seen anything like it before. It was something like this:

\section{Rain is falling from the sky \\ Hitting the ground like drum sticks}

When Ben was about eleven or twelve years old there was a serial book about dinosaurs that came out each month. He would always make me buy a copy each month. I thought that it was a boring book and wasn't sure if he could understand it. When we read the book together Ben would use a lot of im- 
agination in the narrative. I asked a hearing friend to check that Ben could understand the book properly, and apparently he could. That was impressive.

Sue: To us, reading was really important. We always encouraged the children to read plenty of books from an early age, and even now, we encourage them to read widely. At the moment we are encouraging them to read the newspaper. It is so important for Deaf children to develop a wide vocabulary as the foundation for their English learning. You need vocabulary in order to build subject knowledge. It is important for children to develop comprehension and for them to understand concepts.

Ava: When Ben was much older, his teachers would always say that he had good English. This was good, but I needed to be sure, so I would still ask questions - how did the teacher really know that Ben had good English, as she did not have good sign language skills? How could the teacher know that Ben always understood the concepts he was reading? Together, this teacher and I discussed ways to check that Ben's understanding of concepts was adequate. We decided to bring in another Deaf person who had good sign language skills AND good English. We then told Ben to read some text, and then to sign it to this other Deaf person. This Deaf person was then able to tell me that the translation was correct, so I was now satisfied. I am sure that the teacher was, too.

\section{COMMUNICATING WITH HEARING PEOPLE}

Sue and Ava: Deaf parents are relaxed about communication. For us there is no anxiety provoking discussion about whether or not our children will have hearing aids and be oral, or whether or not they will use NzSL. We encourage any visual prompts such as lip-reading, note-taking and observation. We know that if our children use NZsL then this reduces misunderstandings among family members, and reduces any embarrassment that may result from miscommunication. We know that using NZSL keeps our children safe, as we can explain to them the safety rules.

Ava: When Ben was growing up I did not have a lot to do with other parents of Deaf children. Ben and I communicated the same way, so it was easy. I could see that other mothers and Deaf children communicated in different ways, and it was not easy to watch. The mothers would also worry about their children, so I would always say, 'The children are fine, they will be ok.' Other mothers would worry about hearing aids and speech. I would worry about making sure that Ben was accessing education and learning. 
Because both Ben and I are Deaf, we have been very heavily involved in the Deaf community. However, I have always known that he must also interact with hearing people. I grew up with hearing parents and learnt how to function in the hearing world, and I needed Ben to know how to interact with hearing people, too. It is important for all Deaf children to be flexible within both the Deaf community and the hearing world. I remember that when we moved into a new house, the children in the neighbourhood would come and encourage Ben to play with them. I watched him playing with them and realised that Ben was not comfortable, so I talked to him about learning how to mix with hearing people. Now Ben is able to move happily among Deaf and hearing people, and in fact, his partner is hearing.

One more thing, when we visit my parents we switch our communication style to incorporate many of the home signs used when my Deaf brother and I were young. My hearing brother understands this, too, so we are able to communicate together as a family - including Ben.

Sue: It has been good to see both Tessa and Simon become actively involved in groups such as Cubs, Brownies, Scouts and Girl Guides. Both have been to Scouts and Girl Guides Jamborees at which they had a great time.

Ava: Ben went to Cubs when he was six. I said that it would be good for him and made sure that there would be an interpreter there for him. It was great. When the leader was talking, I would tell Ben to look at the interpreter (this was a good way to teach Ben about interpreters), and it was good. Ben loved the activities, and I enjoyed being able to talk with the other mothers there, as the interpreter would be there. Eventually Ben found it hard to keep up with the small talk between the boys. He missed not being able to participate in all of the conversations, and I knew from my experience that it is hard to feel part of a hearing group, so I allowed him to leave.

Sue: Both Tessa and Simon like to mix in both the Deaf and hearing communities. Tessa has a lot of hearing friends; she is social and more assertive. Simon has plenty of hearing friends at school, too, but they don't tend to socialise together at the weekend.

DEAF IDENTITY

Sue: It is very important for Deaf children to grow up with a Deaf identity. When I was growing up I lacked my own Deaf identity and felt very mixed up. I travelled overseas, and it was while I was in England that I was able to 
develop my Deaf identity. I went into Deaf Clubs there and saw lots of Deaf people together. I saw oral Deaf people mixing with signing Deaf people. I saw people who used spoken and sign languages. When I was growing up my family did not know about sign language or Deaf culture. My mother hated it when people signed around her. She would brush it away as she thought it was an eyesore. Now she accepts it, but it is too late for her to learn. Even now, both my mother and sister chose the medical field for their profession and cannot understand my Deaf world. If they were able to migrate to my world they would have a much better understanding of my family and me.

With my children now, Simon has a better sense of his own identity as a Deaf person. He is more forward and talkative with Deaf people, whereas Tessa is shy. At intermediate school Tessa was part of the enrichment class where they often worked on individual projects. Tessa's teacher encouraged her to do one on hearing loss and deafness as an attempt to make her more aware of her own hearing loss and her identity. It is interesting to see that it is full of facts but does not include information about herself or our family. There were no Deaf Mentors (Deaf people who can visit Deaf children in mainstream schools to share their language and culture) available to work with our children. It is a good service for children in mainstream schools now. It is hard for our mainstream students to develop a good Deaf identity, and the Deaf Club is not an appropriate place for young Deaf people as there is a bar there.

Ava: There was one valuable thing that I learnt from Stephen, a Deaf son of Deaf parents, through a conversation that we had one day about being a Deaf child of Deaf parents. Stephen was saying that the one time that he would feel uncomfortable was when he brought home his Deaf friends. His parents would chat with them, as they were interested in his friends. Stephen's Deaf friends, however, were in awe of his parents, as most of their parents couldn't sign. Here they were chatting away with Stephen's parents on a range of topics. Stephen himself felt frustrated, as they were his mates who had come to visit him, not to hang out with his parents!! He didn't mind short conversations, but resented long involved discussions. For me, this was a real eye opener, and from then on, when Ben brought his Deaf friends home, I made sure that I had a short conversation with them then left them to 'hang out' as mates do!

THE IMPORTANCE OF EDUCATION TO OUR DEAF FUTURE

Sue and Ava: Deaf parents have high expectations of our Deaf children as far as educational achievement is concerned. Deaf children of Deaf parents arrive at school having had the opportunity to develop good language skills, to 
become better adjusted and better socialised, and have more positive attitudes than do most of the Deaf children of hearing parents who may have missed effective communication in their early years. Our children understand our Deaf way. From within our Deaf culture we can access any of the following:

- the use of hearing aids and cochlear implants;

- speech therapy;

- sign language;

- Deaf schools; and

- mainstreaming.

Sue: Following her experiences at the kindergarten, Tessa really made the decision herself to attend a mainstream school with an itinerant teacher of the Deaf visiting. Simon had the same experience as Tessa and so followed her lead.

Sue and Ava: As parents, we felt that it was important for our children to have a good education to make their lives easier, and that they needed to be able to read anything relating to the world around them. Teaching language development regardless of whether a child is hearing or Deaf is crucial. The more they have before they start school, the better they will do in school. We have always made sure that our children have known how to make decisions for themselves and what works for them. It is important for Deaf children to have choices.

Ava: When Ben turned five he started school at Sumner Primary School. At that time there was a Deaf Unit there. In Form 1, Ben was fully mainstreamed, but he was not happy, so I asked him why. Ben explained clearly to me that the other children talked all of the time, and he felt lonely and left out. The teacher aide would do his work for him and he wasn't learning! The teacher aide wanted Ben to do good work so that it looked like she was working well, and to do this, she gave him the answers!! I was amazed and realised that this twelve-year-old boy was a confident communicator and was able to express himself clearly.

Ben then moved to van Asch School for the Deaf, and he was so happy there. All of the children were Deaf, and all signed, but here, also, I could see that he was not learning. Ben would say that this was poor teaching, but I knew that it could have been Ben not making an effort to learn. I would repeatedly explain that it is important to learn and to have a good education. 
Sue and Ava: Deaf parents are very fussy about the quality of their Deaf children's education. We want our children's education to meet their needs. Individual Education Plans (IEPs) are very important in helping to ensure that our children have access to the curriculum and to an education that matches their aspirations. One of our concerns has been around how present educational approaches can be changed so that they develop our children's skills in conceptual thinking. We know that there are no Deaf dependent limits on the intellectual developments of our children.

Sue: We have noticed that literacy development is delayed in Deaf classes compared with hearing classes. The lessons are repetitive, and this impairs our children's language development. We believed that there were more opportunities for Tessa and Simon to learn English in a hearing class, and they were challenged more. How can a small class with only four or five children be challenged??

At the high school level our children have become more assertive about what they want. Tessa in particular hates having professionals around her. She wants to be independent and show that she can do it herself. Simon is visited by an itinerant teacher of the Deaf and says that one visit a week is enough. Both Tessa and Simon are strong hearing aid wearers. They don't want to wear an FM system as it restricts their freedom. They want to come and go from class to class like their peers.

It is important to build up a relationship with the Special Education Needs Coordinator (sEnco) in the school. Deaf parents have to watch how their children are going, and they are in a position to explain to the SENCO what they need. Our SENCO is wonderful and will listen to and follow up our concerns. Sometimes we can see hearing parents of Deaf children make the wrong choices and can see the children suffer.

Sue and Ava: Too many Deaf children experience a traumatic journey before finding the Deaf world. We worry about how such traumatic experiences impact on some Deaf parents' resources for parenting the next generation of our culture. Some Deaf parents, whose educational achievements were low, struggled with low self-esteem and did not have the nurturing environment of a Deaf family and the Deaf community. They often question their ability to be good parents. There are few places for such parents to turn for advice. A Deaf parent who is secure in their cultural identity and who is given advice by a health professional or a professional in Deaf education, will often recognise when their experience and knowledge is greater than that of the professional. 
They will ignore the professional advice and feel assured that their child is just Deaf. They can go home and draw on the cultural resources of the Deaf world where they are supported and encouraged. This situation is a reason for arguing for Deaf children to have connections with Deaf adults from an early age. It is also a reason for advocating for educated Deaf adults so that the resources available within the Deaf community are of the highest calibre.

We value the difference that technology such as faxes, teletext televisions and computers have made to our lives. They have broadened our horizons. We can now communicate more easily with our Deaf friends and family using mobile text phones and e-mail. We see hearing aids as important for our children because we want them to learn to listen and speak so that they become bilingual and bicultural. It is important to us that our children have skills that enable them to communicate with both Deaf and hearing people. We believe that this will enable them to become independent learners and help them to continue to have confident and positive identities and strong self-esteem.

When Deaf people grow up in the Deaf world and, through their educational opportunities, become bilingual and bicultural, this expands our minds. We want to travel and to learn about the ways that people within other cultures live. We want to share our experiences so that all of the Deaf children who follow us have the best possible opportunities to fulfil their potential and contribute positively to both the Deaf and hearing worlds.

NOTES

1 An FM system is an additional assistive listening device. 